\title{
PEMANFAATAN KONSEP SPACE WITHIN A SPACE DALAM PENGOLAHAN LAYOUT PADA INTERIOR
}

\author{
Ananda Trisiana ${ }^{1}$, Ully Irma Maulina Hanafiah , Titihan Sarihati \\ Prodi S1 Desain Interior, Fakultas Industri Kreatif, Universitas Telkom \\ trisiana.ananda88@gmail.com
}

\begin{abstract}
Abstrak. Ilmu pada bidang interior telah banyak digunakan oleh masyarakat untuk menambah nilai value dan memberikan solusi permasalahan ruang interior. Salah satunya adalah banyaknya desainer menerapkan konsep ruang open plan untuk memberikan solusi desain ruang agar terasa luas, terasa cerah, dan memungkinkan untuk melakukan aktivitas secara bersamaan. Akan tetapi terdapat beberapa aktivitas yang tidak dapat dilakukan secara bersamaan seperti ruang privasi yaitu, kamar mandi, ruang rapat dll. Dengan adanya kebutuhan tersebut biasanya area privasi diletakkan di luar area open plan sehingga penggunaan open plan dalam interior tidak mengalami perkembangan dalam pengolahan ruang interior. Padahal terdapat empat cara fundamental dalam menghubungkan beberapa ruang salah satunya adalah space within a space. Dengan mengadaptasikan, mengembangkan, mengkombinasikan dan menggunakan hubungan antar ruang space within a space, konsep open plan dapat menciptakan ruang yang menarik dan dapat memenuhi fungsi bangunan. Dalam penelitian ini metode yang digunakan ialah deskriptif analisis yaitu, dengan cara mendeskripsikan dan menganalisa konsep space within a space yang telah diterapkan oleh arsitek dan desainer banguan terkenal ke dalam layout interior. Manfaat dari penelitian ini adalah memberikan alternatif pengolahan ruang interior pada konsep open plan agar terciptanya variasi desain. Tujuan dari penelitian ini adalah memberikan perspektif baru dalam pengolahan konsep dari open plan dengan cara penerapan space within a space untuk memisahkan fungsi ruang sehingga perancang dapat memberikan ruang privasi dalam area publik, (atau sebaliknya) tanpa merubah esensi konsep open plan tersebut.
\end{abstract}

Kata kunci : Interior, Open plan, Ruang, Space within a space

Abstract. Science in interior design has been widely used by the community to add value and provide solutions to problems in interior space. One of them is the number of designers applying the concept of open plan to provide space design solutions to feel spacious, feel bright, and make it possible to carry out activities simultaneously. However, there are several activities that cannot be carried out simultaneously such as privacy spaces, namely bathrooms, meeting rooms etc. With these needs, the privacy area is usually placed outside the open plan area so that the use of open plan in the interior does not experience development in the processing of interior space. Even though there are four fundamental ways of connecting several spaces, one of them is space within a space. By adapting, developing, combining and using relationships between spaces within a space, the concept of open plan can create attractive spaces and can fulfill building functions. In this study the method used is descriptive analysis, that is, by describing and analyzing the concept of space within a space that has been applied by famous building architects and designers into interior layouts. The benefit of this research is to provide an alternative to processing interior space in the open plan concept in order to create a variety of designs. The purpose of this study is to provide a new perspective in processing concepts from an open plan by applying space within a space to separate space functions so that designers can provide privacy space in public areas, (or vice versa) without changing the essence of the open plan concept.

Keywords: Interior, Open plan, Space, Space within a space

\section{PENDAHULUAN}

Ruang merupakan hasil dari bertemunya tiga dimensi yang menghasilkan suatu volume yang mengelilingi sekitar (Ching, 2007:102). Di dalam ruang terdiri dari beberapa zona yang menghasilkan perbedaan aktivitas seperti zona publik, privasi, dan servis (Grimley, 2007:92104). Prinsip dasar open plan merupakan sebuah ruang yang tidak seluruhnya tertutup atau ruang yang terpisah (Ching, 1995:216). Dengan konsep open plan ini setiap aktivitas dapat dilakukan dalam satu ruang secara bersamaan sehingga dapat membuat ruang terkesan luas, informal dan menarik. Akan tetapi aktivitas publik dan privasi tetap tidak dapat digabungkan tanpa pemisah ruang. Mengutip dari majalah Forbes, terdapat artikel yang mendiskusikan 
apakah konsep open plan pada kantor telah mati. Dari artikel tersebut Charlotte mengatakan bahwa pada dasarnya kantor menggunakan ruang yang fleksibel dan menurut Ann-Fleming Powell, para pekerja menginginkan konsep open plan untuk dapat berkolaborasi tetapi tetap ada ruang privasi untuk berinteraksi (Oyler, 2017). Dengan permintaan penggunaan ruang seperti itu, membuktikan bahwa open plan telah mengalami stagnan sehingga diperlukan pembaruan dalam pengolahan ruang. Untuk dapat menciptakan ruang yang lebih atraktif, maka perlu melihat prinsip dasar hubungan antar ruang agar layout ruang lebih menarik dan memberikan fungsi ruang yang berbeda, salah satunya adalah space within a space.

Bagaimana jika ruang privasi dan ruang publik digabungkan tanpa merubah esensi dari open plan? Pertanyaan ini menjadi alasan apakah open plan diterapkan hanya untuk ruang-ruang tertentu yang fungsinya dapat digabungkan dalam satu area sehingga membuat fungsi tertentu yang tidak dapat bergabung harus dibuat terpisah keluar dari area open plan.

Pembahasan jurnal ini memiliki tujuan untuk memberikan perspektif baru dalam pengolahan konsep open plan dengan cara menggunakan hubungan antar ruang space within a space. Dalam jurnal ini akan terlihat bahwa dengan menggabungkan area privasi di dalam area publik (atau sebaliknya) dapat menjadi layout yang menarik dan menjadi sebuah objek didalam ruang yang dapat dilihat dari analisa pembahasan studi kasus. Dengan penerapan space within a space ini akan memberikan manfaat untuk memberikan alternatif dalam pengolahan ruang interior.

\section{INTERPRETASI KONSEP SPACE WITHIN A SPACE}

Menurut Peter Zumthor (Pop, 2015:375) di dalam arsitektur terdapat dua dasar dalam komposisi ruang. Yang pertama ialah bangunan arsitektur tertutup yang dimana mengisolasi setiap ruang di dalamnya, dan bangunan arsitektur terbuka yang menghubungkan setiap ruang tanpa memiliki batas. Berdasarkan pemahaman Peter Zumthor tentang bangunan arsitektur, maka tercipta sebuah ruang interior yang terdapat dalam bangunan tersebut.

Pada dasarnya, setiap interior akan mengisi sebuah ruang yang dapat didefinisikan dengan batas dinding, lantai, dan plafon. Ruang interior harus diperhatikan proporsi bentuknya sehingga tercipta ruang yang harmonis. Proporsi ruang tidak hanya berbicara bentuk persegi, tetapi dapat berbentuk lingkaran oval, bahkan bentuk yang lebih kompleks ( Grimley, 2007:78).

Untuk dapat menerapkan space within a space perlu memahami apa itu konsep open plan. Menurut Francis D.K. Ching (1995:216) Open plan adalah sebuah floor plan yang tidak memiliki batasan ruang. Biasanya open plan terdiri dari susunan bebas furnitur yang dimana membuat group berdasarkan aktivitasnya. Open plan banyak digunakan untuk menggabungkan beberapa aktivitas, contohnya ruang keluarga, ruang tamu, dan ruang makan yang digabungkan. Pada kantor biasanya seperti ruang kerja yang bergabung.

Konsep open plan memiliki kekurangan dan kelebihan pada penggunaannya. Keuntungan dari open plan pada kantor seperti kemudahan berinteraksi antar kolega dan kekurangannya adanya dampak kebisingan yang mengakibatkan kurangnya privasi (Kim, de Dear 2013:12-13). Dari kekurangan tersebut dapat menerapkan konsep space within a space sebagai solusi desain.

Komposisi ruangan open plan yang ideal merupakan suatu hal yang penting agar dapat mencapai konsep space within a space dengan benar. Ruangan kecil yang dihasilkan oleh konsep ini sangat tergantung dari ruangan utama. Ketika proporsi ruang kecil tersebut tidak sesuai dimensinya maka ruang utama tersebut akan kehilangan fungsinya karena luasan yang menyempit dan juga kehilangan estetika bentuk (D.K. Ching, 2007:186). Untuk menghindari 
masalah tersebut, dapat menggunakan beberapa strategi seperti: menggunakan elevasi lantai dimana ruang tersebut diletakkan; menciptakan ketinggian plafon untuk menghadirkan volume; memberikan transparansi untuk menyamarkan batas antara ruang dalam dan luar; dan penggunaan organisasi open plan pada layout interior. ( Higgins, 2015:29).

Konsep space within a space dapat dicapai dengan cara meletakkan sebuah ruang kecil didalam ruang dengan volume lebih besar, sehingga terlihat seperti sebuah objek di dalam ruang tersebut. Ruang kecil tersebut dapat dihubungkan menjadi sebuah objek skulptural di sebuah galeri (Higgins, 2015:48). Secara singkat dapat dijelaskan bahwa sebuah ruang yang luas dapat mencakup beberapa ruang yang lebih kecil di dalamnya ( Higgins, 2015:50).

Strategi ini membuat ruangan yang kecil tersebut menjadi sebuah ruang dengan aktivitas berbeda. Dengan cara memberikan bentuk yang berbeda, perbedaan warna dan material, permainan cahaya, dan juga perbedaan treatment penutup ruang dengan area sekitarnya sehingga memberikan efek fungsi dan kepentingan ruang yang berbeda (Higgins, 2015:50).

Menurut Francis D.K. Ching (1995:218) space within a space disebut sebagai embedded space atau dapat diartikan sebagai ruang yang dibungkus atau di integrasikan_sebagai bagian penting pada ruangan yang lebih besar. Sedangkan berdasarkan Alfirevic (2016:24), di dalam teori dan praktek arsitektur terdapat beberapa interpretasi tentang konsep space within a space: 1) bangunan diantara ruang terbuka, 2) ruang terbuka diantara ruang urban, 3) ruang terbuka diantara bangunan arsitektur, 4) dan fungsi ruang independen diantara bangunan open plan.

Menurut Rapoport (dalam Alfirevic, 2016:25) pada istilah inner space banyak yang mengartikan sebagai ruang dalam yang berarti bisa disebut atrium, skylight, atau apapun ruangan yang dikelilingi oleh struktur bangunan dimana mereka berlokasi. Alfirevic juga mengatakan (2016:25) terdapat relasi antara dua kategori spasial yang berbeda dan telah berkembang pada masa modern tentang konsep open plan. Pada contoh pertama arsitektural kontemporer dimana ruang dalam dikelilingi oleh beberapa ruang dan didefinisikan sebagai larger open plan. Pada praktek arsitektur, terdapat berbagai cara untuk membedakan ruang tersebut seperti perubahan dimensi, bentuk, material, warna, tekstur, level cahaya, dll.

Dalam konklusinya, Alfirevic (2016:38) mengatakan pendekatan space within a space dapat membentuk ruang sebagai ruang yang fungsional, berkembang berdasarkan kebutuhan untuk membuat fungsi terntu didalam sebuah bangunan. Tidak hanya sebagai konsep spasial, tetapi dapat juga menyoroti dimensi dan visual didalam ruang interior bangunan. Lalu konsep space within a space juga dapat menciptakan ruang teknikal untuk keperluan tertentu. Hal ini berkembang berdasarkan keinginann untuk membuat kelompok ruang tergantung pada fungsinya seperti, kamar mandi, dapur, toilet, sauna,dll. Ruang dengan fungsi seperti ini dapat dibentuk menjadi fungsi yang freestanding untuk meminimalisir beberapa jumlah instalasi seperti pemipaan air bersih, dll. Selain itu konsep ini juga dapat memberikan efek perseptif, yang berkembang dari keinginan untuk mencapai suatu efek visual melalui stratifikasi dan segregasi ruang, sehingga dapat menyambungkan sebuah bentuk dan tema pada suatu bangunan.

\section{METODE PENELITIAN}

Sifat penelitian ini adalah deskriptif analisis, yaitu dengan cara mendeskripsikan dengan konsep space within a space yang telah diterapkan oleh arsitek bangunan terkenal kedalam layout interior. 
Adapun pengertian dari metode deskriptif analisis menurut Sugiono (2008:29) adalah sebuah metode yang mendeskripsikan atau memberi gambaran objek yang diteliti melalui data yang dikumpulkan sebagaimana adanya dan tanpa mengambil kesimpulan. Oleh karena itu penelitian deskriptif analisis memusatkan kepada masalah yang ada dan hasil dari penelitian tersebut dilakukan analisa untuk diambil kesimpulan.

\section{TINJAUAN STUDI PRESEDEN}

Konsep space within a space telah digunakan oleh banyak arsitek ternama, salah satunya adalah Ludwig Mies Van Der Rohe dalam karyanya Farnshworth House (gambar 1). Rumah ini didesain untuk Dr. Edith Farnsworth sebagai rumah peristirahatan. Masa bangunan dikelilingi oleh alam dan faktor ini dimanfaatkan oleh Mies untuk memperlihatkan konsep yang kuat dari hubungan antara interior dan alam (Zimmerman, 2006).

Bentuk yang sangat sederhana diperlihatkan oleh Mies dengan cara menggunakan kaca pada interior sehingga alam dan cahaya natural dapat masuk ke dalam rumah (gambar 1). Mies berpendapat bahwa warna dan interior fitting tidak boleh mengganggu bentuk dan warna dari bentuk arsitektur tersebut sehingga dibuatlah sebuah box besar yang berisikan fitting interior seperti dapur, kamar mandi, dan lemari untuk menyederhanakan konfigurasi ruang interior (Zimmerman and Gössel, 2006). Dengan menyatukan fitting interior tersebut, Mies dapat mencapai layout open-plan sehingga bentukan kotak tersebut terlihat seperti sebuah objek yang kokoh (gambar 2).

Secara layout, jelas bahwa konsep yang digunakan merupakan open-plan (gambar 2), mengintegrasikan beberapa ruang kedalam sebuah ruang yang lebih besar sehingga ruang tersebut menjadi lebih besar dan menetralisir batas ruang antar aktivitas (Alfirević, 2016:24). Konsep space within a space diterapkan untuk menyatukan kamar mandi, lemari, dan dapur sehingga secara visual tidak terdapat banyak objek vertikal yang dapat mengganggu fasad bangunan yang terbuat dari kaca dan baja.

Selain itu terdapat pula contoh lain dari The Glass House karya dari Philip Johnson. The glass house (gambar 3) merupakan karya yang terinspirasi dari Mies (Alfirević, 2016:27). Dilihat dari denah, terlihat jelas rumah ini menggunakan konsep tradisional dari ruang keluarga tetapi tidak menggunakan sekat ruang sehingga terciptanya open plan (gambar 4). Walaupun tidak

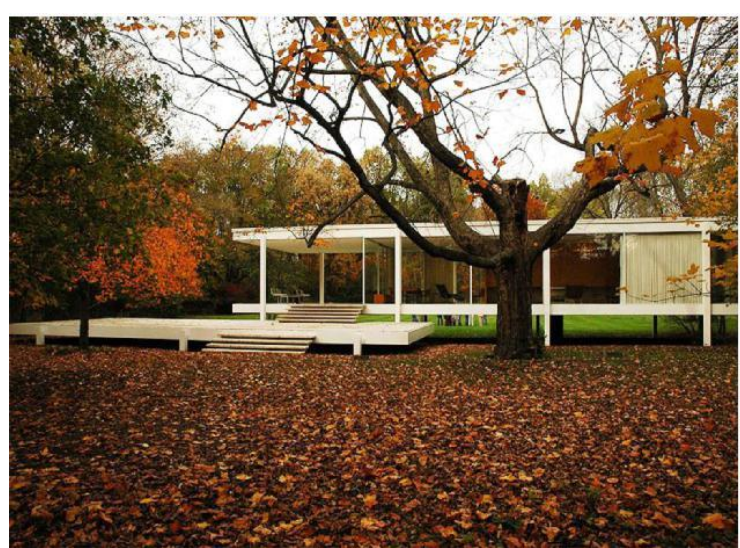

Gambar 1 Rumah Fansworth House karya Ludwig Mies

Van Der Rohe

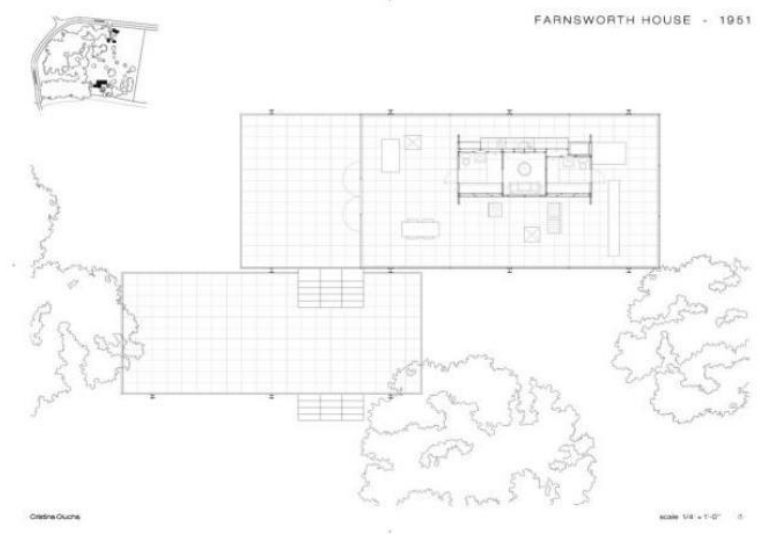

Gambar 2 Denah Fansworth House 


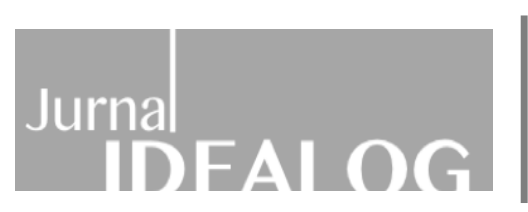

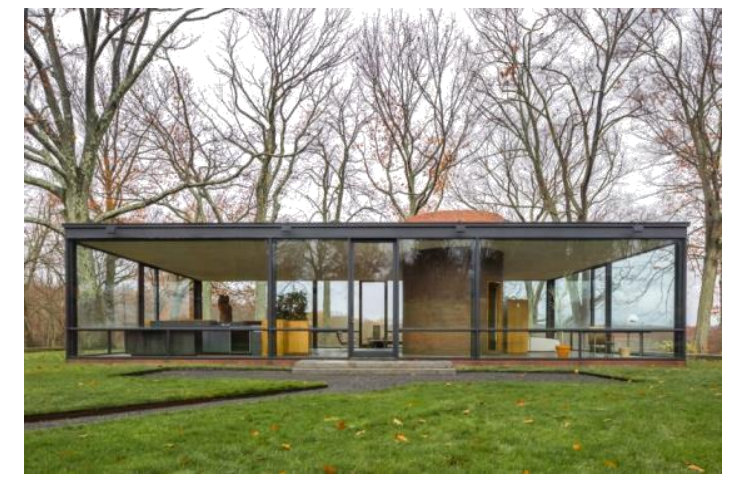

Gambar 3 Glass House karya Philip Johnson, terinspirasi dari Mies Van Der Rohe

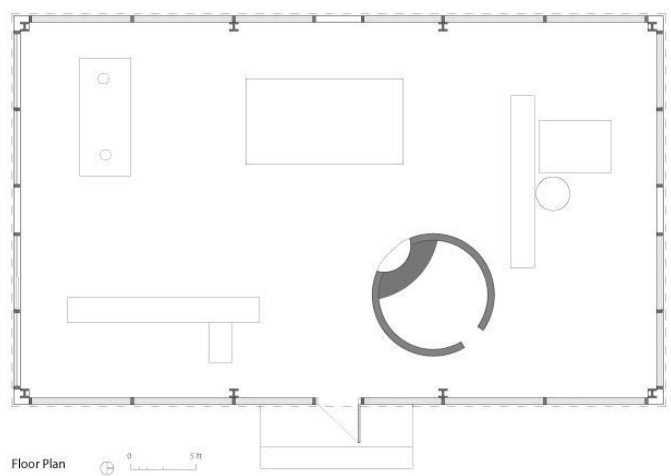

Gambar 4 Denah dari rumah Glass House karya Philip Johnson

memiliki partisi ruang, rumah ini memilik program ruang yang lengkap seperti dapur, area makan, ruang keluarga, area tidur, kamar mandi dan pintu masuk utama (Divisare, 2016, Philip Johnson Glass House, https://divisare.com/projects/326504-philip-johnson-simongarcia-glass-house, di akses tanggal 17 Agustus 2018).

Secara layout, pemisah aktivitas menggunakan perubahan tekstur dan warna seperti penggunaan karpet sebagai penanda ruang keluarga. Untuk kamar mandi sendiri diperlukan pemisah ruang yang solid dan ruang privasi untuk menyembunyikan aktivitas pribadi (gambar 4).

Strategi space within a space terlihat jelas pada denah dengan memisahkan kamar mandi dengan ruang lain sebagai respon keperluan aktivitas privasi. Pendekatan ini dapat terealisasikan karena adanya konsep open plan yang tidak memiliki sekat interior sehingga startegi ini membentuk sebuah bentuk silinder (Alfirević, 2016:24).

Dengan berubahnya trend interior dan arsitektur, maka konsep space within a space juga telah berinovasi akibat dari proses kreatif. Seperti yang dilakukan oleh UNO8A dalam proyek PB Studio (gambar 5), dimana alih-alih menggunakan open plan untuk mengintegrasikan setiap aktivitas, PB studio memisahkan ruang privasi dari studio foto dan living room menggunakan strategi space within a space.

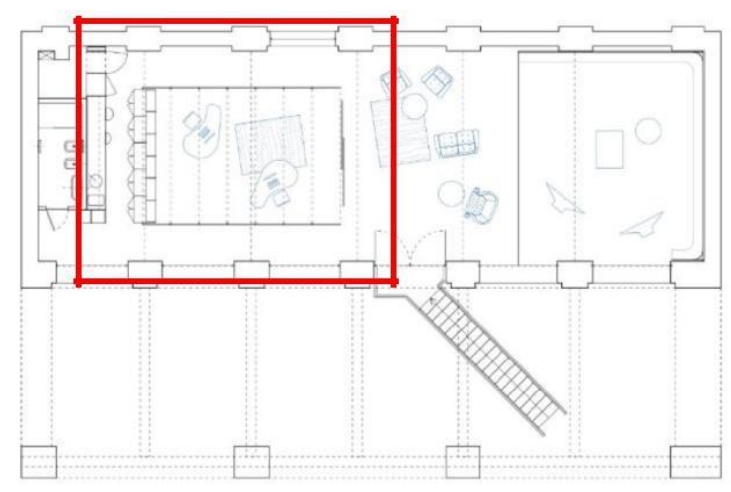

Gambar 6 Denah PB Studio karya dari UNO8A

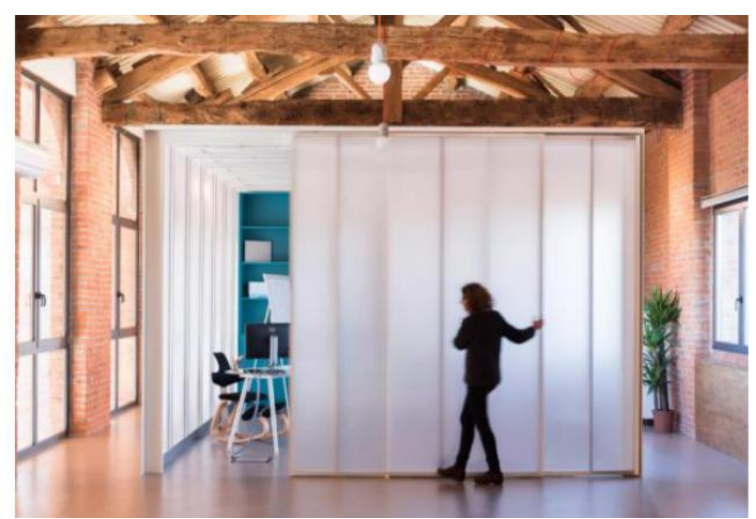

Gambar 5 Penggunaan konsep space within a space menggunakan material polikarbonat. 
UNO8A mencoba untuk merespon bentuk bangunan yaitu persegi panjang dan menaruh sebuah dimensi ruang di tengah bangunan dengan memberikan sirkulasi di setiap sisi ruang. Strategi space within a space, tidak hanya menggunakan material dinding solid sebagai pemisah, tetapi dapat membedakannya dengan cara permainan kontras material, tekstur atau keduanya (Bernardotti, 2017).

Penggunaan material pada office box tidak hanya sekedar estetika, tetapi memiliki tujuan tersendiri. Pada partisi office box menggunakan panel polikarbonat untuk memberikan intimasi dan terang pada sebuah interior kantor (Bernardotti, 2017) (gambar 6). Dari itu, konsep space within a space dapat didefinisikan dengan konteks bangunan, seperti gelap terang suatu bangunan sehingga pemilihan material dapat membantu penekanan konsep space within a space.

Berbeda pendekatan dengan UNO8A, Eduard Eremchuk membuat sebuah fashion retail dengan pendekatan museum-like showroom, Likeshop Showroom (gambar 7), yang berlokasi di Rostov, Rusia dan menempati pada bangunan bersejarah dengan langit-langit yang tinggi dan jendela lengkung. Total area perancangan adalah 46 meter persegi (Yellowtrace, 2018,

Like Shop Showroom In Rostov-On-Don by Eduard Eremchuk, https://www.yellowtrace.com.au/eduard-eremchuk-like-shop-showroom/\#gallery-8, diakses tanggal 20 Agustus 2018).

Konsep space within a space digunakan untuk mendefinisikan area fitting room pada retail (gambar 8). Area fitting room menggunakan box yang ditutupi dengan material berbulu berwarna pink sehingga memberikan aksen warna dan tekstur dalam interior (gambar 7). Penggunaan perbedaan warna dan tekstur tersebut menjadikan ruang ganti sebagai sebuah objek instalasi seni yang terintegrasi dengan interior dan mendefinisikan sebuah ruang yang dapat digunakan ( Higgins, 2015:50).

Seperti Eduard Eremchuk, Studio desain dari Koasia, Brigada, mencoba untuk membuat konsep space within a space dengan lebih kompleks. Mereka menggunakan kontras gelap terang (gambar 11), bentuk, dan kesederhanaan dalam mencapai pendekatan anti-exhibition,

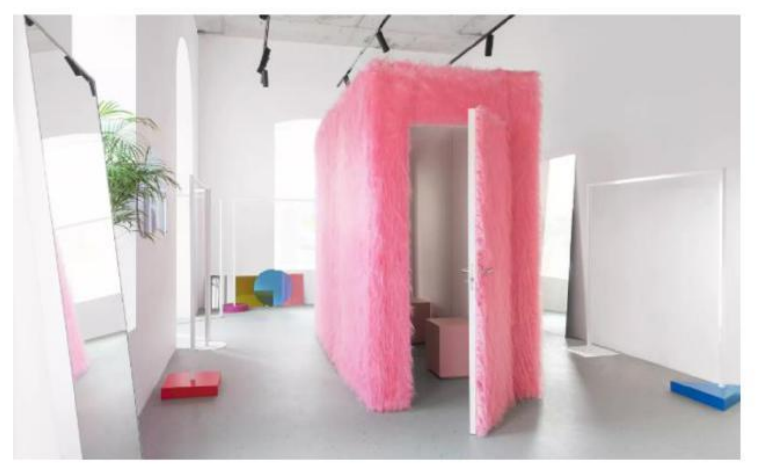

Gambar 7 Konsep space within a space yang menjadi objek sculptural yang berestetika.

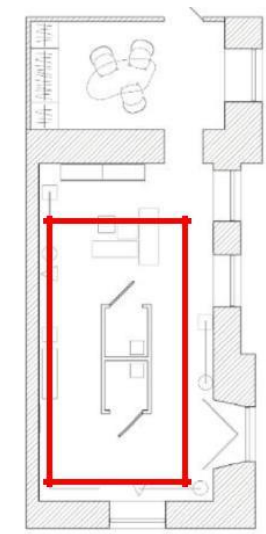

Gambar 8 Denah dari Likeshop Showroom 


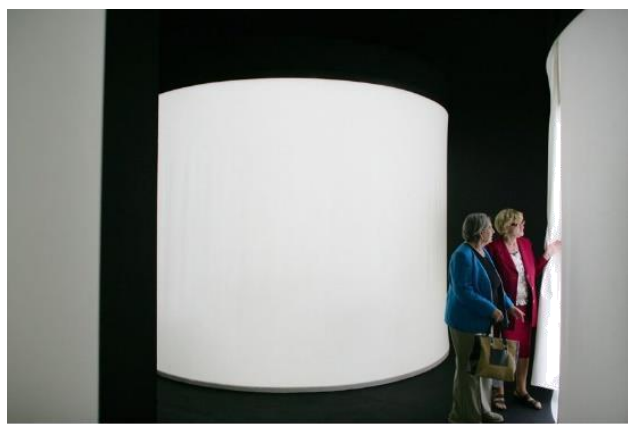

Gambar 9 Konsep space within a space digunakan untuk mendukung konsep anti-exhibition.

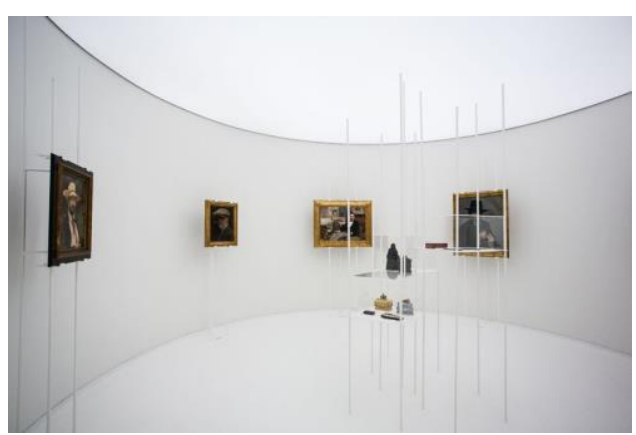

Gambar 10 Interior area pameran dengan konsep space within space yang memberikan efek penasaran.

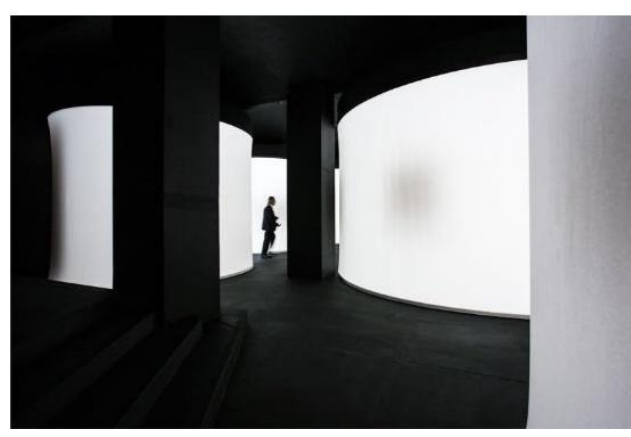

Gambar 11 Konsep space within a space yang terdiri dari beberapa ruang didalam ruang inspace, konsep ruang yang kontras antara eksisting dan ruang space within a space tata display pameran yang menyembunyikan konten dari museum itu sendiri (Copeland, Lovay, 2017)

Untuk menghasilkan Organisasi space within a space, Brigada membuat 'nonspace' yang menjadikan permainan persepsi terhadap perbedaan level gelap terang (gambar 9). Dengan cara transformasi dan menutupi semua elemen eksisting menjadi warna hitam, ruang pamer konvensional menjadi hilang dan mereka membuat ruang-ruang baru yang berbentuk silinder berwarna putih (gambar 9) yang mengingatkan kembali akan bentuk asap rokok silinder (Lalueta, Metalocus, 2013, Culture of smoking: From Taboo to

Taboo by Brigada, https://www.metalocus.es/en/news/culture-smokingtaboo-taboo-brigada, di akses tangga 17 Agustus 2018).

Organisasi space within a space tersebut menghasilkan atmosfir baru seperti kesan misteri, petualang, dan menjadikan pengunjung tertarik untuk masuk terus menerus untuk melihat karya favorit mereka (gambar 10) (Lalueta, Metalocus, 2013, Culture of smoking:

From Taboo to Taboo by Brigada, https://www.metalocus.es/en/news/culture-smokingtaboo-taboo-brigada, di akses tangga 17 Agustus 2018).

\section{HASIL DAN DISKUSI}

Space within a space merupakan organisasi ruang khusus didalam ruang eksisting, dimana setiap pengaplikasiannya menghasilkan efek dan estetika.

Untuk dapat mencapai konsep ini, perlu memperhatikan proporsi ruang eksisting terlebih dahulu sehingga dimensi space within a space dapat ideal. Selain itu, strategi tersebut juga dapat diaplikasikan dengan konsep open plan, dimana semua aktivitas diintegrasikan ke dalam satu ruang sehingga batas aktivitas menjadi samar. Space within a space dapat diterapkan pada aktivitas yang berbeda dalam satu ruangan sehingga area tersebut diberikan batas dengan memberikan permainan warna, tekstur, dan material yang kontras dengan eksisting. Penerapan ini dapat kita lihat pada rumah Fansworth House karya Mies Van Der Rohe dan Glass House karya Philip Johnson.

Dalam proyek PB Studio karya UNO8A dapat dianalisa bahwa mereka telah merancang sebuah kantor dengan kebutuhan ruang seperti ruang fotografi, area tunggu, dan kantor pribadi. Kebutuhan ruang tersebut digabungkan menjadi satu sehingga menciptakan konsep open plan, 
yang dimana dapat meminimalisir batasan ruang. Seperti yang dikatakan oleh Francis D.K.Ching (1995:216) bahwa ruang open plan merupakan ruang yang tidak memiliki batasan, sehingga banyak menggunakan furnitur sebagai pembatas ruang semu.

Akibat dari kantor pribadi yang membutuhkan privasi, mereka menciptakan sebuah ruang tetapi mereka juga tetap memperhatikan proporsi ruang karena ruang interior yang kecil. Jika hal tersebut tidak diperhatikan maka ruang tersebut akan kehilangan fungsi dan estetikanya (Ching:1995:216). Dengan alasan tersebut, mereka menggunakan konsep space within a space karena ruang privasi merupakan ruang khusus yang tidak dapat digabungkan dengan ruang lain tanpa batas visual sesuai dengan perkataan Francis D.K. Ching tentang embedded space. Ruang yang diciptakan menggunakan konsep space within a space sehingga berada diantara empat sirkulasi dan tidak melekat pada sisi bangunan. Setiap sisi bangunan dapat meneruskan cahaya natural dan menjadikan ruang interior mendapatkan pencahayaan alami disetiap sisinya. UNO8A mencoba membentuk ruang dengan material kontras antara ruang induk menggunakan batu yang bertekstur kasar, dengan ruang anak, menggunakan polikarbonat yang bertekstur lembut. Pemilihan polikarbonat juga memiliki pertimbangan agar ruang tersebut mendapatkan cahaya matahari karena sifatnya polikarbonat yang dapat meneruskan cahaya. Teknik yang digunakan oleh UNO8A sejalan dengan perkataan Higgins (2015:50) dan Alfirevic (2016:25) bahwa perubahan ruang space within a space dapat diciptakan dengan permainan kontras antar material dan level cahaya.

Berbeda pendekatan dengan proyek sebelumnya, Likeshop Showroom karya Edward Eremchuk membuat showroom dengan membagi ruang yang bersebelahan menyesuaikan dari denah eksisting. Pada area utama yaitu showroom mode busana yang memiliki konsep open plan dengan ruang serba puth dengan sifat memantulkan cahaya. Pada showroom terdapat ruang yang tidak dapat dimasukan kedalam konsep open plan showroom, yaitu ruang ganti pakaian yang memiliki aktivitas privasi, sehingga membutuhkan batasan ruang. Edward Eremchuk menciptakan ruang ditengah ruang open plan dengan bentuk yang unik sehingga ruang tersebut seperti sebuah objek skulptural. Alfirevic (2016:38) pun juga mengatakan bahwa konsep space within space dapat menciptakan efek perseptif dalam memisahkan ruang sehingga terlihat seperti objek yang menarik.

Edward Eremchuk menggunakan material berbulu berwarna pink, yang dimana memiliki sifat meresap cahaya sehingga kontras dengan warna putih yang memantulkan cahaya. Warna pink ini juga menjadi aksen ruang sehingga menjadi bentuk yang menarik. Edward Eremchuk juga memperhatikan proporsi ruang, ruang eksisting memiliki plafon yang tinggi sehingga Edward Eremchuk membuat ruang ganti dengan plafon lebih rendah untuk menciptakan efek sebuah objek yang berdiri disuatu ruang besar. Permainan ruang dan proporsi ruang yang dilakukan oleh Edward Eremchuk dapat dibilang berhasil dan sejalan dengan perkataan Higgins dalam membentuk ruang yang menarik dan ruang yang dapat menjadi objek skulptural.

Pada karya Studio Brigada, mereka menerapkan konsep space within a space dengan menggunakan kontras gelap terang, bentuk, perbedaan ketinggian pada tata display sebuah pameran. Terlihat dari pengolahan ruang yang dihasilkan membentuk sebuah silinder- silinder 
yang terang didalam sebuah ruang besar yang gelap sehingga menjadi suatu objek yang kontras. Studio Brigada mencoba untuk memperlihatkan dimensi visual yang berbeda dari ruang induk. Apa yang dilakukan oleh Studio Brigada sesuai dengan perkataan Alfirevic (2016:38) dimana ruang tersebut dapat menjadi ruang fungsional didalam sebuah bangunan. Ruang yang diciptakan dengan bentuk silinder memiliki fungsi sebagai area pamer.

\section{KESIMPULAN}

Penelitian ini berhasil menyimpulkan bahwa konsep space within a space telah dimulai dari Mies Van Der Rohe dalam karyanya bertajuk Fansworth House. Kemudian diikuti oleh Philip Jhonson dengan karyanya The Glass House. Konsep space within a space pada era desain kontemporer menjadi lebih menarik karena konsep space within a space tidak hanya memisahkan aktivitas tetapi telah menjadi sebuah ruang yang menciptakan nilai estetika.

Oleh karena itu untuk perancangan konsep open plan dapat mempertimbangkan hubungan antar ruang space within a space untuk menciptakan perspektif baru dalam pengolahan ruang. Dengan menambahkan space within a space kedalam open plan, dapat menjadi sebuah solusi untuk ruang open plan yang membutuhkan kolaborasi tetapi tetap membutuhkan ruang privasi yang tidak menginginkan intervensi pengguna ruang lainnya. Space within a space juga dapat menambah nilai estetika ruang karena memberikan efek perspektif seperti sebuah objek skulptural yang menarik.

Adapun konsep space within a space dapat diterapkan pada situasi permasalahan seperti berikut:

1. Ruang kantor, dengan konsep open plan dan ingin menambahkan ruang privasi seperti ruang conference, kantin, ruang istirahat dll.

2. Perpustakaan, dengan area baca yang tenang dan menambahkan ruang diskusi atau ruang istirahat tanpa harus keluar dari zona area baca.

3. Rumah tinggal, menggabungkan area sesuai kebutuhan instalasi seperti kamar mandi dan dapur sehingga dapat meminimalisir pemasangan instalasi pemipaan, dan saluran air bersih dan kotor.

4. Retail, yang menginginkan area ganti ditengah ruang sehingga dapat terlihat jelas dengan bentuknya tanpa tambahan signage.

5. Museum dengan menghadirkan konsep non-space atau konsep anti-museum dimana objek pamer disembunyikan didalam ruang-ruang yang lebih kecil untuk memberikan efek penasaran dan adiktif.

6. Dan masih banyak situasi permasalahan yang dapat diterapkan berdasarkan kreatifitas perancang.

Penelitian ini dapat memberikan landasan ide baru dalam pengolahan elemen pembentuk ruang sehingga kemudian hari desain dapat terus berkembang dan berinovasi. 


\section{DAFTAR PUSTAKA}

[1] Alfirevic, D., \& Simonovic Alfirevic, S. (2016). Interpretations of Space Within Space Concept in Contemporary Open-Plan Architecture [Primena koncepta prostor u prostoru u savremenoj arhitekturi otvorenog plana]. Arhitektura i urbanizam, 24-40.

[2] Ching, F. D. (1995). A Visual Dictionary Of Architecture. New York : Van Nostrand Reinhold.

[3] Ching, F. D. (2007). Architecture: Form, Space, and Order 3rd ed. New Jersey: John Wiley \& Sons, Inc. .

[4] Devabhaktuni, S. (2009). A Little Place Called Space. AA Files, 74-77.

[5] Divisare, T. (2016, September 23). Philip Johnson Glass House. Diambil dari Divisare: https://divisare.com/projects/326504-philip-johnson-simon-garcia-glass-house

[6] Divisare, T. (2017, March 16). UNO8A PB Studio. Diambil dari Divisare: https://divisare.com/projects/339957-uno8a-pb-studio

[7] Grimley, C., \& Love, M. (2007). Color, space, and style: all the details interior designers need to know but can never find. Rockport Publisher .

[8] Higgins, I. (2015). Spatial Strategies For Interior Design. London: Laurence King Publishing Ltd.

[9] Jungsoo Kim, R. d. (2013). Workspace Satisfaction: The Privacy-communication trade-off in open-plan offices. Journal of Environmental Psychology, Diambil dari https://escholarship.org/uc/item/2gq017pb.

[10] Kim, R. (2009). The tectonically defining space of Mies van der Rohe. ARQ: Architectural Research Quarterly, 251-260.

[11] Krier, R. (1979). Urban Space. London: Academy Editions.

[12] Mathieu Copeland, B. L. (2017). The Anti-Museum : An Anthology. Koenig Books.

[13] Metalocus, \& Lalueta, I. (2013, February 18). Culture of smoking: From Taboo to Taboo by Brigada. Diambil dari Metalocus: https://www.metalocus.es/en/news/culture-smoking-taboo-taboo-brigada

[14] Oyler, M. (2017, Oktober 3). Is The Open - Office Plan Dead? Diambil dari Forbes: https://www.forbes.com/sites/bisnow/2017/10/03/is-the-open-office-plandead/\#5fc2fa9e5ae5

[15] Pantouvaki, S. (2012). A Space within a Space: Contemporary Scenographic Approaches in Historical Theatrical Spaces. In M. F. anderson a., The Visual in Performance Practice: Interdisciplinary Perspectives. Oxford: Inter-Disciplinary Press.

[16] Pop, D. (2015). Theorising Between Space and Place A Case Study on Perceptive Architecture-Serpentine Gallery Pavilions. Philobiblon Vol. 20 Iss. 2, 356-381.

[17] Sugiyono, P. D. (2008). Metode Penelitian Kuantitatif, Kualitatif, dan R\&D. Bandung: Alfabeta.

[18] Yellowtrace, T. (2018, April 27). LIKE SHOP SHOWROOM IN ROSTOV-ON-DON, RUSSIA BY EDUARD EREMCHUK. Diambil dari Yellowtrace: https://www.yellowtrace.com.au/eduard-eremchuk-like-shop-showroom/\#gallery-8

[19] Zimmerman, C. (2006). Mies van der Rohe. Hong Kong: Taschen. 